\title{
OUTCOME COMPARISON FraMEWORK FOR DESIGN COURSES IN ENGINEERING AND TECHNOLOGY
}

\author{
Sima Zakani ${ }^{1,}$, Jake Kaupp ${ }^{2}$, Roderick Turner ${ }^{3}$, Brian Frank ${ }^{2}$ \\ ${ }^{1}$ University of British Columbia, ${ }^{2}$ Queen's University, ${ }^{3}$ Seneca College of Applied Arts and Technology \\ *sima.zakani@hiphealth.ca
}

\begin{abstract}
Inconsistent transfer policies, lack of articulated syllabi, and subsequent differences on the delivery of comparable courses are a few examples of the obstacles that Ontario students face when trying to change programs. This study sought to develop a framework to support transfer between engineering and engineering technology programs in Ontario using explicit and implicit course outcomes to help develop and define new pathways.

Primarily focusing on program expectations in introductory design courses this study compared the content and context of design projects in different institutions and programs across the province. The contextual framework, namely the "Outcome Comparison Framework for Engineering and Technology", synthesized relevant elements from existing frameworks which can collectively identify the differences in the context of learning in engineering and technology disciplines. This framework looks into disciplinarity, use of tools and design thinking required to successfully finish a design project.

We collected design projects from 5 technology programs and 4 engineering programs across the province and coded them based on the content targeted by the project description and the three dimensions of the framework.

Content analysis for design courses showed an overall low percentage of alignment between the learning outcomes and the project descriptions across the board. It was found that engineering design courses were more focused on principles of engineering design (problem definition, stakeholder needs, idea generation, decision making) and development of professional characteristics (workplace communication skills, ethics, etc.); but technology design courses, focused on the use of more "hands-on"' skills (building/implementation, troubleshooting, etc.)
\end{abstract}

Keywords: Learning outcomes, transfer and articulation, engineering technology education

\section{INTRODUCTION}

Ontario's higher education system presents challenges to students wanting to transfer between programs. Inconsistent transfer policies, lack of articulated syllabi, and differences in the delivery of comparable courses are a few of these challenges that have existed for decades. However, a recent shift in the university sector to define course and program level learning outcomes provides an opportunity to explore new approaches.

Learning outcomes describe capabilities of students by the end of a period of study as described by the educator: what they would know and what they would be able to do. Quality assurance and improvement, as well as teaching and learning have greatly benefited from the assessment of learning outcomes. However, despite the fact that most postsecondary institutions have moved toward embedding learning outcomes, effective assessment of learning outcomes is challenging [1]. Learning outcomes can be a highly valuable tool for professionals involved in improving existing transfer pathways of increasing the overall number of transfer opportunities [2].

There are different transfer models and systems in North America, European Bologna, etc. [3]. However, certain issues such as the wording of learning outcomes, autonomy at the institutional level, and discrepancies in definition of credits within and between different sectors limit the successful implementation of these transfer models [4]. This study sought to develop a framework to support transfer between engineering and engineering technology programs in Ontario using explicit and implicit course outcomes to help develop and define new pathways.

We assumed most transfers happen from the end of a technology program to an engineering program, or from the middle of an engineering program to a technology program. So, two subject-specific frameworks were developed; one for common courses in calculus and physics, and one for engineering design courses, which is the focus of this article. 
Table 1. Outcome comparison framework for design courses in enqineering and technology

\begin{tabular}{|l|l|l|l|}
\hline \multicolumn{1}{|c|}{ Dimension } & Level 1 & Level 2 & Level 3 \\
\hline Disciplinarity & $\begin{array}{l}\text { Requires knowledge of one } \\
\text { specific engineering discipline }\end{array}$ & $\begin{array}{l}\text { Using first principles of mathematical } \\
\text { knowledge, natural sciences and } \\
\text { engineering sciences }\end{array}$ & $\begin{array}{l}\text { Requires knowledge of different } \\
\text { engineering disciplines }\end{array}$ \\
\hline Use of Tools & $\begin{array}{l}\text { Apply appropriate techniques, } \\
\text { resources, and modern } \\
\text { engineering and IT tools }\end{array}$ & $\begin{array}{l}\text { Select and apply appropriate } \\
\text { techniques, resources, and modern } \\
\text { engineering and IT tools, including } \\
\text { prediction and modelling }\end{array}$ & $\begin{array}{l}\text { Create, select and apply appropriate } \\
\text { techniques, resources, and modern } \\
\text { engineering and IT tools, including } \\
\text { prediction and modelling }\end{array}$ \\
\hline Design Thinking & $\begin{array}{l}\text { Identify and select and } \\
\text { implement solutions to } \\
\text { engineering problems reaching } \\
\text { substantiated conclusions }\end{array}$ & $\begin{array}{l}\text { Identify, explore, select and implement } \\
\text { solutions to engineering problems } \\
\text { reaching substantiated conclusions }\end{array}$ & $\begin{array}{l}\text { Identify, explore, select, implement } \\
\text { and evaluate solutions to engineering } \\
\text { problems reaching substantiated } \\
\text { conclusions }\end{array}$ \\
\hline
\end{tabular}

It is very common in the university sector for the students to be exposed to a relatively non-technical design project in first year, and a very technical capstone design project in the last year [5]. The college sector, on the other hand, heavily relies on developing discipline specific practical skills integrated in laboratory courses throughout the program and design projects in the later years. We started by looking at existing frameworks and identified three relevant elements which can collectively identify the differences in the context of learning design in engineering and technology disciplines. This framework borrows certain elements of the graduate attributes as described by the International Engineering Alliance [6] and competencies listed by the Higher Education Quality Council of Ontario [7]:

Disciplinarity looks into the context in which a design project is given to the students and tries to capture the subtle differences between projects aiming for student competency in one specific discipline and projects aiming to assimilate multidisciplinary scenarios as found in real world applications.

Use of Tools looks into integration of practical handson skills in the context of engineering/technology design projects and how the students could be trained to either follow a prescribed technique, select amongst a few possible options or creatively come up with their own method.

Design Thinking looks into the different steps in a design project and tries to identify the presence of principals of design such as literature search, problem definition, idea generation, idea evaluation, implementation, design reflection, etc.

These dimensions were measured through a comprehensive assessment of project descriptions in each sector.

\section{METHODS}

We requested learning outcomes and representative assignments from programs for analysis. Material from design courses were selected for piloting the framework as they are important for transfer and represent a range of knowledge and skills. We collected learning outcomes from 5 technology programs and 4 engineering programs across the province; only one technology program and three engineering programs shared project descriptions. Projects and learning outcomes were coded first based on the content and then assessed in the three dimensions of the framework.

For the assessment of course learning outcomes for design courses, content areas were drawn from Queen's University's syllabi for engineering design courses and vocational learning outcomes in Ontario's engineering technology program standards. Some other content areas (such as general/specific building/implementation skills, general/specific tools for testing/trouble shooting, design test, design evaluation, and computer aided design (CAD)) were added to the list after reviewing sample course materials.

\section{RESULTS}

Figure 1 summarizes the content areas found in the design courses in both learning outcomes (either explicitly listed in course descriptions or implicitly found in marking rubrics) and project descriptions for participating institutions. There is much more information about learning outcomes (leftmost cluster in Figure 1) than project descriptions (centre cluster in Figure 1) as schools were generally comfortable sharing course learning outcomes and rubrics (5 technology programs and 4 engineering programs), but only 1 technology program and 3 engineering programs were willing to share project descriptions. The two lists were also compared to examine alignment between outcome expectations and tasks (rightmost cluster in Figure 1).

There is considerable similarity between the design courses in engineering and technology programs; however, engineering design courses are more focused on principles of engineering design (problem definition, stakeholder needs, idea generation, decision making) and developing professional characteristics (workplace communication skills, ethics, etc.). Technology design courses have greater 


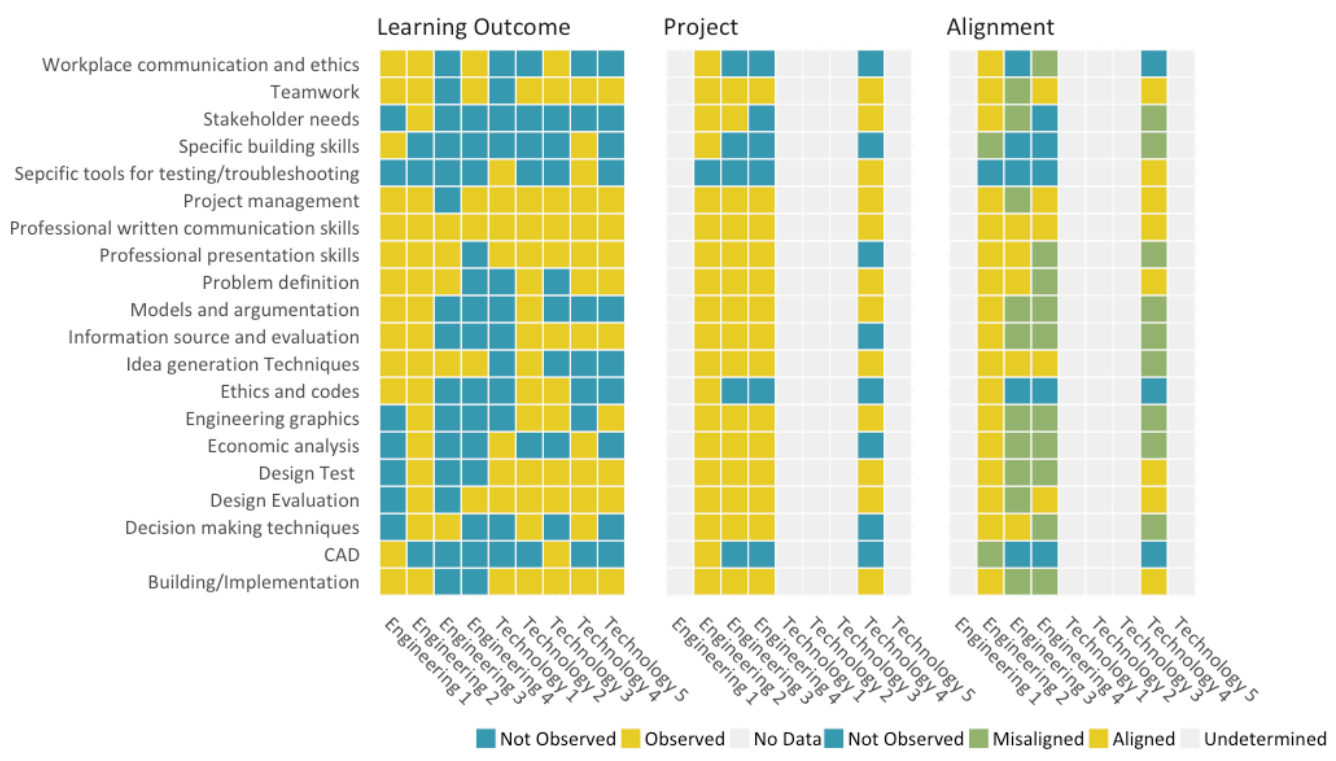

Fig. 2. Alignment between content areas mentioned in explicit learning outcomes and design project descriptions. The left chart summarizes content areas observed (yellow)/not observed (blue) in the explicit learning outcomes. The middle chart summarizes content areas required as project deliverables in design courses from institutions that provided project descriptions. The right chart summarizes the content areas that were missing in both learning outcomes and project description (blue), observed in one but missing in the other (green), or observed in both (yellow).

focus on the use of more "hands-on" skills (building/ implementation, troubleshooting, etc.).

The analysis of alignment was only possible for the four institutions that provided project descriptions. There was a low percentage of alignment between the learning outcomes (both implicit and explicit) considered and the project descriptions across the board, with the exception of engineering program 2 . This reduces confidence in the data collected.

Figure 2 shows the design activity ratings for the four participating schools based on the design activity rubric. Project descriptions from college 4 were all defined within three levels of disciplinarity. Interestingly, while the technology projects only required application of appropriate techniques and resources, engineering design courses tend to gravitate towards selection and application of tools from a wider range of techniques and the use of modelling and prediction. Design projects from this particular technology program only required identification, selection and implementation of solutions with no focus on researching different solutions and idea generation (coded as "explore") and/or constructively criticizing the solutions and reflection (coded as "evaluate").

\section{DISCUSSION}

Engineering/Technology design courses are specifically intended to enable students to apply knowledge from mathematics (elements of algebra, calculus, differential equations, probability, statistics and numerical analysis) and science courses (elements of physics and chemistry, etc.) to projects that emulate activities in the discipline. Ideally, these projects are designed to give the student a chance to implement design process methods and tools, problem analysis and economic analysis, while practicing their engineering communications skills, professionalism and ethics.

Assessment of engineering and technology design courses was very challenging. It was initially planned to separately assess practical hands-on skills in the context of laboratory courses. However, due to limited time, the diverse needs of knowledge in assessing laboratory skills for different disciplines, and the hesitance from programs in sharing material from such courses, the attention was shifted towards measuring such abilities within the context of design courses. That is why for the assessment of course learning outcomes for design courses, content areas were a combination of syllabi from Queen's University's engineering design courses and Ontario's engineering technology program standards. Results showed that, except for one institution, there was a low percentage of alignment between the learning outcomes and the project descriptions across the board. While the design courses in engineering and technology programs seemed to be mostly similar, there seemed to be a significant difference in how these programs expect a design course to be. Engineering design courses are found to be more focused on principles of 


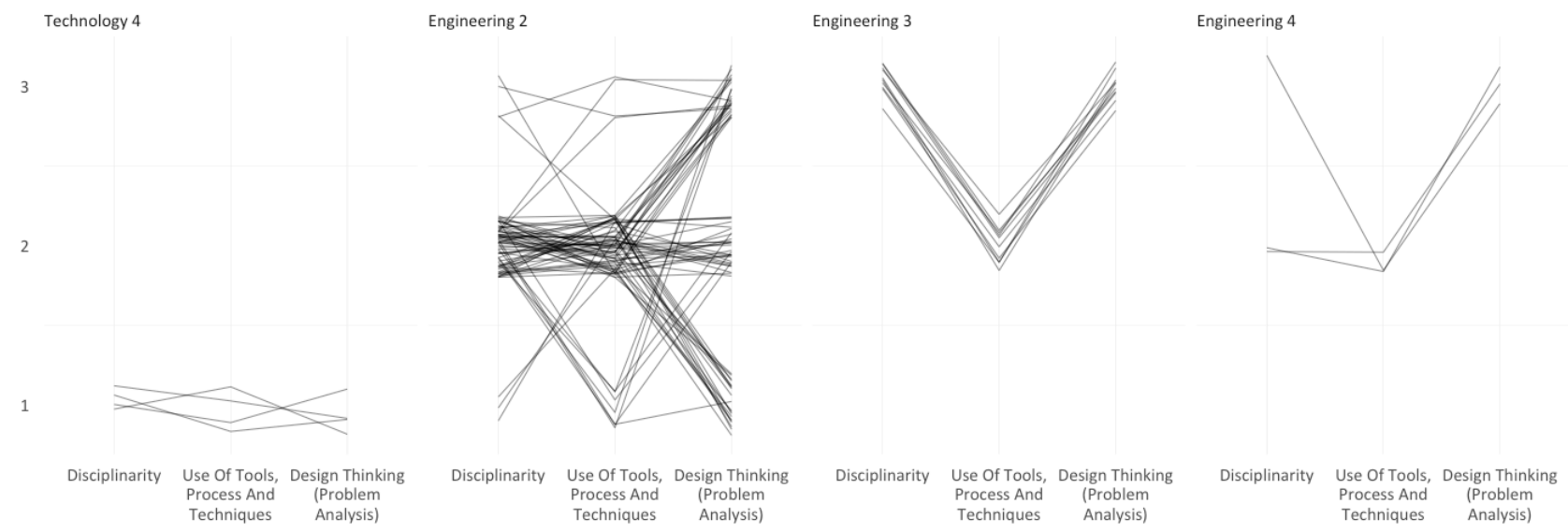

Fig. 3. Results from coding the learning outcomes for design projects in each program (each line represents the coding of one project). Levels 1-3 correspond to the levels of each dimension shown in Table 1.

engineering design (problem definition, stakeholder needs, idea generation, decision making) and development of professional characteristics (workplace communication skills, ethics, etc.). Technology design courses seem to be focused on the use of more "hands-on" skills (building/implementation, troubleshooting, etc.).

The current study was limited by its sample size, so the findings regarding some of the differences might lose their significance in a larger ensemble of institutions. This report is part of a larger study focusing on three types of introductory courses; however, the overarching study is limited by only assessing cognate domain indicators. It is possible that in-depth analysis of other contributing factors such as self-regulation would reveal other information with regards to the differences in the learning habits and the impact of being part of a college vs university society, etc.

\section{ACKNOWLEDGEMENTS}

We would like to acknowledge ONCAT for funding this research project. We also would like to thank the participating institutions and the programs and individuals who provided data and their feedback.

\section{REFERENCES}

[1] Lori Goff, Michael K. Potter, Eleanor Pierre, Thomas Carey, Amy Gullage, Erika Kustra, Rebecca Lee, Valerie Lopes, Leslie Marshall, Lynn Martin, Jessica Raffoul, Abeer Siddiqui, Greg Van Gastel, 2015, Learning outcomes assessment a practitioner's handbook.

http://www.heqco.ca/sitecollectiondocuments/heqco.loahand book_eng_2015.pdf

[2] Irene Carter, James P. Coyle, Donald R. Leslie, 2011, "Easing the transfer of students from college to university programs: How can learning outcomes help?," The Canadian Journal of Higher Education, 41(2):10
[3] Finola Finlay, 2009, Credit transfer: Models and systems in $B C$, North America and beyond, special report. http://www.bccat.ca/pubs/sr_transfermodels.pdf

[4] John FitzGibbon, 2014, Learning outcomes and credit transfer: Examples, issues, and possibilities. http://www.bccat.ca/pubs/Learning_Outcomes_and_Credit_ Transfer_Feb2014.pdf

[5] Brian Frank, David Strong, Richard Sellens, Lynnan Clapham, 2013, Progress with the professional spine: A four-year engineering design and practice sequence. Australasian Journal of Engineering Education, 19(1):6374.

[6] International Engineering Alliance, 2013, Graduate attributes and professional competencies. http://www.ieagreements.org/IEA-Grad-Attr-ProfCompetencies.pdf

[7] Mary Catherine Lennon, Brian Frank, James Humphreys, Rhonda Lenton, Kirsten Madsen, Abdelwahab Omri, Roderick Turner, 2014, Tuning: Identifying and measuring sector-based learning outcomes in postsecondary education. http://www.heqco.ca/SiteCollectionDocuments/Tuning\%20 ENG.pdf 